\title{
Entre currais e modelos: Eurico Alves leitor de Feira de Santana, 1940-1960
}

\section{Clóvis Frederico Ramaiana Moraes Oliveira (UNEB)}

Comte, citado por Halbwachs, observava que o equilíbrio mental deriva, em boa parte, do fato de os objetos materiais com os quais mantemos contato diário não mudarem ou mudarem pouco, nos oferecendo uma imagem de estabilidade. $\mathrm{O}$ autor de $A$ memória social acrescenta que este espaço conhecido, e relativamente imóvel, é um meio de apoio importante para a memória dos grupos e que períodos de instabilidades seguem as transformações espaciais (HALBWACHS, 2006, p. 157). Partindo desse principio, pode-se enfrentar os processos de fragmentação de paisagens como um importante deflagrador de problemas da memória, em especial do mais temido deles, o esquecimento. Esquecer, por definição, é apagamento de rastros, que cria impedimentos para os procedimentos de lembrança. O esquecimento pode ter duas veredas, a destruição dos parâmetros físicos que permitem o reconhecimento do vivido, incluindo aqui todas as formas de escritura, e as interdições de práticas cotidianas que conduzem à memória instantânea, habitual (RICOEUR, 2007, p. 425).

As transformações urbanas exercem pressão sobre essas duas formas de rastros, mudando os aspectos visuais, casas, ruas, subúrbios e questionando as práticas ordenadoras do espaço público. Assim, a cidade se constitui em lócus privilegiado para a investigação das tensões entre esquecimento e memória, escrita e apagamento. $\mathrm{O}$ estranhamento de alguns personagens com o resultado de reformas urbanísticas pode, 
também, construir pistas interessantes para a investigação das relações enunciadas anteriormente, sobretudo aqueles atores históricos que se constituem naquilo que Pesavento chama de leitores privilegiados do urbano, os que possuem habilitações dotadas de um olhar refinado, arguto (PESAVENTO, 1995, p. 284).

Dois personagens surgem ao longo destas anotações: a cidade de Feira de Santana entre os anos de 1940 e 1960 e um dos seus leitores, Eurico Alves Boaventura (19091974). A primeira viveu, nas décadas escolhidas como recorte, um surto de urbanização que a consolidou como um dos centros urbanos mais importantes do interior do nordeste. $\mathrm{O}$ segundo experimentou o período urbanizador de sua terra natal, preso entre o encantamento e o estranhamento de quem já não se reconhece no lugar onde nasceu. ${ }^{1}$ Dessa dicotomia, nasceu sua obra magna, Fidalgos e vaqueiros, texto maturado e escrito ao longo das décadas de quarenta e cinquenta do século XX (BOAVENTURA, 1989 p. 11 e 12). Considerando a coincidência entre a escrita do livro e a escrita urbana que se realizava em Feira de Santana, as motivações da elaboração do primeiro podem ter ligações com as mudanças vivenciadas pela segunda e, dessa forma, o livro funcionar como uma alegoria da história da cidade.

Existe um texto que traz a síntese de algumas das preocupações que animaram Eurico Alves Boaventura na elaboração de Fidalgos. Nessa escrita o autor demonstra o não reconhecimento do tecido urbano que se configurava na sua Feira de Santana natal. Eurico estranhava os sons, as ruas, as pessoas e as práticas que cruzavam a paisagem da urbe. Na montagem do inventário da diferença foi escolhido, como o primeiro assunto, as sonoridades, os barulhos que o impediam de exercitar as sua lembranças e reconhecer a sua cidade:

E a praça mudou mesmo. Até o nome mudou na velha Praça do Comércio. Tolice esta de mudar-se o antigo apelido da vetusta praça. Praça da Bandeira...deixe-se esta história de bandeira, que seu lugar é no coração da gente. E acabou-se. E o povo que não tem velhas praças, que não conserva velhos nomes de ruas, não sabe o que é bandeira. (BOAVENTURA, 2006, p. 90).

A opção de dialogar com os sons emitidos para pronunciar os antigos nomes da urbe, longe de uma simples implicância com novidades, é uma metáfora das divergências de Eurico com os caminhos adotados pela urbanização da sua terra natal. Uma delas, explicitada na citação, diz respeito às denominações das artérias públicas. A maior parte das vias, na região central, era conhecida por denominações populares, ou, mais precisamente, oriundas do uso popular. Algumas vias recebiam topônimos 
de acordo com a utilização que lhes era dada nos dias de feira Beco da Esteira (Eram vendidas manufaturas de cipós, de palha de ouricuri), Beco do Mocó (Caças), Rua da Sola (Artefatos de couro) e a Praça do Comércio, junto ao Mercado, que era o principal ponto de encontro do conclave semanal. Mas, a caminhada pelos antigos nomes podia lembrar órgãos que ocupassem os logradouros, a Praça da Cadeia, Beco do Ginásio, Beco do Asilo. Ou ainda pela posição em relação à organização da cidade: a Rua Direita, Rua do Meio. Outras, pelo papel ocupado no meretrício, de Cima e de Baixo, ou ainda o Beco do Bom e do Barato, ocupado por prostitutas que ofereciam serviços mais em conta.

Os nomes elencados acima podem ser classificados como descritivos em oposição aos oficiais, de caráter comemorativo. Os nomes que descrevem eram nascidos dos usos que lhes dava a população, das formas de falar que obedeciam ao movimento da feira, a encenação da indicação com os lábios ou com o olhar. Eram denominações surgidas da oralidade, com sonoridade própria e rituais de escolha.

A substituição dos nomes indica uma mudança no foco de origem dos mesmos: saíam os falares das ruas, para a entrada das sérias reuniões da Câmara de Vereadores. Essa transferência de poderes significava um aumento da área de influência do poder público sobre a cidade; dito com outras palavras, uma presença maior do Estado nas escolhas que ordenavam a urbe e, por conseqüência, uma inibição das vozes gestadas nas artérias públicas de Feira de Santana.

As novas motivações em que se pautavam as escolhas, longe das descrições, objetivavam consolidar memórias em torno de alguns vultos/símbolos nacionais, figuras da história local ou, como pode ser visto em vários casos, homenagens a pessoas que tivessem dirigido a ereção de alguma obra em Feira de Santana. ${ }^{2}$ A nominação feita com estes sentidos tirava de cena as formas de uso da cidade, apagava memórias surgidas do comércio popular, dos chistes urbanos. A preocupação em afastar nomes, os descritivos e eventuais chistes, já estava nas mentes dos vereadores desde a década de 1920, como pode ser observado no seguinte parecer exarado pela comissão de infra-estrutura do Conselho Municipal:

A comissão infra-afirmada, tendo em vista o projeto de lei anexo, e, considerando que é realmente justo o que se pretende com o mesmo projeto, uma vez que, aberta com esta a dita Travessa, se deve sem demora dar-lhe um nome para evitar que se venha depois, como sempre acontece, dar-lhe alguma denominação imprópria, e ainda porque o nome escolhido é perfeitamente aceitável, é de parecer que seja discutido e aprovado o dito projeto. ${ }^{3}$ 
Para um conhecido pensador alemão, a fixação dos nomes dos logradouros cristalizava a imposição de uma forma de leitura verticalizada para os transeuntes (BENJAMIN, 1989, p.44). Essa imposição apagava os registros oralizados dos nomes de ruas, empurrando-os para os esquecimento e substituindo as práticas de nomear pela fala por ações burocráticas. Referências fundamentais de uma memória topográfica, as artérias públicas perderiam as sonoridades que lhes conferiam uma história, restando a forma escrita, como mecanismo de imposição de um sentido único. Essa rua, nomeada a partir das instâncias do poder, limita as possibilidades de escrita da cidade por parte das camadas populares e dificulta outras leituras do mundo urbano. A reação de Eurico, portanto, é contra um movimento de re-ordenação dos pontos de construção dos sentidos urbanos, uma re-escrita da história de Feira de Santana a partir de critérios oriundos do poder público.

Além dos movimentos enunciados mais acima, a escolha por iniciar o inventário sentimental pela ausência de sons que remetem à infância pode ter outras motivações. A partir do final da década de quarenta, sobretudo com a abertura das rodovias Transnordestina e Rio-Bahia, ${ }^{4}$ a cidade experimentou um notável crescimento demográfico, tendo o seu centro urbano partido de pouco menos de vinte mil habitantes, no censo de 1940, para cerca de setenta mil no de $1960 .^{5}$

Os dados não permitem fazer uma classificação em torno da origem dos chegantes, todavia, pensando com Ginzburg acerca dos dados indiciários, outras fontes permitem entrever os perfis e fazer uma estimativa dos períodos de chegada mais acentuados (GINZBURG, 1999). Uma carta destinada ao além, escrita pelo jovem estudante Hugo Silva para o poeta Aloísio Resende, morto dez anos antes, traz algumas pistas, permitindo ter uma idéia aproximada acerca do contingente de novos moradores da cidade:

A população sofreu uma extraordinária mudança. Há nortistas e nortistas, como todos os sotaques e todas as peixeiras.

O destacamento policial também cresceu muito, e trabalha febrilmente em dar facadas em paraibanos e receber facadas de paraibanos. ${ }^{6}$

Considerando que o destinatário da missiva morrera em 1941, quando o remetente tinha apenas onze de idade (Nasceu a 29/04/1929), é possível concluir, com pequena margem de erro, que boa parte das pessoas que contribuíram para o crescimento demográfico de Feira de Santana, no período abarcado pelos censos, veio dos demais Estados nordestinos, o que pode ainda ser observado com o cotejo de outras 
fontes, como os processos-crimes, peças nas quais surgem várias pessoas oriundas daqueles Estados como testemunhas, vítimas ou autores de homicídios. (SOUZA, 2008, p. 67)

A chegada de novos moradores a um centro urbano altera significativamente os ordenamentos de uma cidade, são novas práticas que começam a circular pelas ruas da cidade. Também não são raros os conflitos, metaforizados, no caso de Feira de Santana, pelas peixeiras citadas por Silva (1951). Mas, também chegam novos sons, vozes com falares de longe, sotaques que indicam outras formações e, à polifonia urbana, eram incorporadas novas sonoridades, para serem somadas a outras, já existentes.

Os sons trazidos por aqueles que chegavam envoltos na poeira quente da viagem, não passaram despercebidos a Eurico. Em texto publicado em um jornal da capital, o autor traz aos nossos ouvidos algumas sonoridades que vinham com os novos habitantes da Feira de Santana: Cabra da peste! Cabra da bicha! Filho da gota serena! (BOAVENTURA, 2006, p. 84). Todavia, faz questão de demonstrar que estas novas sonoridades não eram mal vindas, produzindo, inclusive, um neologismo para realçar a condição de entranhamento dos novos feirenses: feirensezou-se. O autor considera que as migrações são continuidades de outras, parte de um processo de construção da cidade como uma espécie de referência urbanizadora no sertão nordestino: “(...). O perfume jovem da cidade, melhor da vila que desperta garrida e faceira, chegava até os campos do longínquo Piauí. A notícia do bom comércio, de boa praça voou até lá. E de lá vieram famílias para o comércio novo.” (BOAVENTURA, 1989, p. 397)

Não eram todas as sonoridades que incomodavam o poeta, aquelas oriundas do mundo rural, vinda com tropeiros ou trepada sobre paus-de-arara, não. As narrativas de lutas de famílias e de combates de cangaceiros, chegadas com os novos habitantes, certamente engordavam o mosaico de falas de valentia que compunham o imaginário da chamada Princesa do Sertão. Para Eurico, esta invasão não prejudicava o caminhar da urbe, era parte da projeção histórica de sua terra natal, afinal “(...) O aboio, que impeliu boiadas do Piauí, embalou a marcha da sua gente até os nossos campos. (...).” (BOAVENTURA, 1989, p. 399).

A escolha de metáforas sonoras para começar um texto, ou melhor, para começar textos, já que a forma é recorrente em Eurico, indica que os ouvidos do poeta percebiam novas vozes se insinuando na cena feirense, vozes que se agregavam ao barulho de automóveis, aos sons dos cascos de animais nas pedras do calçamento, os alto-falantes anunciando as novidades nas lojas, ou ainda das emissoras de rádio nos 
receptores, entre elas, duas de Feira de Santana. Os barulhos diferentes, as linguagens estranhas certamente atuavam no sentido de abafar os diálogos oriundos da feira ou as conversas entre fazendeiros satisfeitos com as gritas das chuvas.

No complexo enredo urbano não eram apenas os sons familiares que eram escondidos: "Aquele edifício novo de três andares escondeu a loja de Bráulio Miranda, que enriqueceu na guerra de quatorze" (BOAVENTURA, 2006, p.91). Enquanto historiador, gostaria de começar esta parte das perguntas que faço ao autor com uma desconfiança: quais motivos o levaram a escolher estes três elementos para começar a falar da Paisagem urbana? Creio que só seja possível encontrar respostas inspecionando os detalhes menores do quadro, i.é, não o prédio, mas o ambiente urbano, o que existia em volta dele.

A análise dos livros de Plantas da Prefeitura Municipal ${ }^{7}$ e das cobranças de IPTU, ${ }^{8}$ na década de cinquenta permite vislumbrar que eram raras no centro urbano as construções verticalizadas, na verdade, com o nome de prédio eram apenas três, existindo outras como palacetes, sobrados e armazéns, e a grande maioria de casas. A raridade da construção, como indica o pequeno número delas, pode ter sido uma boa motivação para o autor começar a sua escrita, citando esta mudança. Por outro lado, nada de extraordinário parece ter acontecido com a biografia do proprietário, para ser ele escolhido como referencial para o início da descrição das mudanças físicas. Como Eurico considerava importantes os comerciantes que possuíam um sobrenome vinculado ao trabalho de construção da cidade, o que pode não ser o caso, o comerciante em questão também é uma certa raridade no centro urbano. Nos dois casos, a escolha do prédio não foi aleatória, o que conduz as investigações no sentido de buscar esclarecimentos em torno das opções.

Responder a esta questão é importante para recuperar o itinerário da produção de Fidalgos ou, de forma mais ampla, das leituras que Eurico fazia da Feira de Santana que estava sendo escrita naqueles anos nervosos. Em princípio, pode-se escolher duas pistas para resolver o problema, uma que diz respeito à construção e suas relações com a urbe que se espalhava pelo planalto e outra que é a opção de escolher um comerciante que teria enriquecido na Primeira Guerra Mundial, para enunciar a questão da substituição de memórias.

Começando do começo, ou seja, da escolha de um prédio para ilustrar o raciocínio. O fato de ser incomum na paisagem da cidade, tradicionalmente construída de maneira horizontal, indica a chegada nas terras feirenses de uma nova forma de praticar o lugar, dando-lhe dimensões espaciais articuladas com as cidades que se erguiam 
no Sudeste, ou mesmo na capital do Estado, já então, no final da década de cinquenta, recheadas de prédios de apartamentos e escritórios. Segundo Lefebvre, esta maneira de ocupar o solo urbano, otimizando-o, esgotando-lhe os menores pedaços em favor de uma utilização mais intensiva e rentável, sintetiza a visão do território citadino como valor de troca, descartando, progressivamente, as formas de pensá-lo como valor de uso. O capital sentimental cede lugar às idéias de lucro e utilitarismo (LEFEBVRE, 2001, p. 6).

A visão do espaço urbano como algo cambiável é, certamente, uma das mais graves ameaças à manutenção da visão feirense que confortara a infância de Eurico. As casas que eram também uma forma de museus familiares, moradias onde nasceram os proprietários e os pais destes, passavam a ser avaliadas não pelo valor sentimental, mas pelo que podiam render pecuniariamente. Os lugares da memória que, na acepção de Pierre Nora, são referenciais fundamentais para o exercício da lembrança, e por consequência para a construção das identidades individuais e coletivas, são dissolvidos na agitada relação de compra e venda, a casa/mercadoria era oposta à casa/lembrança (NORA, 1984, p. 9). Pensando com Certeau, o lugar enquanto ponto de estabilidade seria substituído pelo espaço, ou seja, o lugar praticado e, consequentemente, instável, mutante (CERTEAU, 2003, p. 200-201).

Além de atingir as casas propriamente ditas, as transformações que atormentavam a escrita de Eurico atingiam empreendimentos comerciais. Estes estabelecimentos, no discurso rememorador do autor, eram extensões do viver no lar, pontos de encontro para a prosa da tarde, leitura coletiva dos jornais chegados de Salvador ou discussões políticas e negociações de gado. Segundo Paul Ricoeur, existe uma forma de memória, que ele chama de secundária, que necessita de ritos para ser exercitada (RICOEUR, 2006, p. 53); trata-se de uma memória trabalhada cotidianamente em eventos ordinários, no dia-a-dia. Seguindo o caminho trilhado pelo autor citado, defendo que as casas comerciais recordadas pelo poeta eram lugares de memorização, pontos de encontro de narradores, no sentido benjaminiano do termo (BENJAMIN, 1993, p. 203), para a socialização dos saberes, dos casos extraordinários. Nestes conclaves diários, a oralidade era a forma encontrada para tornar comuns as experiências.

Todavia, a sombra ameaçadora das novas edificações, tomando a luz do sol de outras construções mais baixas, prenunciava novas temporalidades, mais nervosas. Anunciava também a chegada de uma nova forma de estabelecimento comercial, lojas que prometiam, nas suas estruturas retas, a substituição da paisagem amiga por outra, simbolizadora de negociações agitadas. Edifício com salas de escritórios alugadas, 
com atividades distintas praticadas sob o mesmo teto, concorriam com as velhas casas comerciais e seus balcões longos. Na outrora tranqüila Rua Sales Barbosa podia ser encontrado o prédio do Banco Econômico, cujas salas dos andares superiores eram utilizadas por profissionais liberais para oferecer serviços novos na cidade. ${ }^{9}$

O fato de a construção apresentada mais acima ser de propriedade de um Banco facilita-me passar à segunda parte da questão, a da data e do nome do comerciante propriamente dito. Creio que também aqui seria interessante dividir o problema em dois aspectos. Começo pela data. A guerra de quatorze é um dos eventos míticos aos quais Eurico atribui a destruição da sociedade pastoril, os demais foram a Proclamação da República e a Revolução de Trinta (BOAVENTURA: 1989). Em Fidalgos, o autor entende que a guerra, com a necessidade de substituição das exportações e o consequente esforço fabril, rompeu o equilíbrio auto-suficiente das casas de fazenda, tornando-as dependentes de produtos oriundos da cidade: "O industrialismo decorrente e forçado pelo conflito de quatorze foi que afetou fundamentalmente a vida rural entre nós, ainda sem outros pontos de apoio além da policultura do fidalgo" (BOAVENTURA, 1989, p. 410). As propriedades rurais, que se assemelhavam a pequenos feudos, são invadidas por uma nova forma de vida e submetidas ao orgulho de uma urbe invasora, esmagadora das memórias sertanejas.

Para além da chegada de mercadorias, a guerra traz mais moedas ou, como prefere o autor, a desvalorização do velho dinheiro. A maior circulação monetária substitui antigos mecanismos de relações comerciais, como o escambo, o compromisso baseado na palavra do comprador, ou seja, no testemunho e nas velhas promissórias. Essas formas de relacionamento são substituídas pela impessoalidade da moeda, pela efígie de um alto figurão da história nacional, ou um símbolo pátrio. Circulando pela cidade, fazendo riquezas repentinas, como parece ser o caso em apreço, o novo dinheiro deslocou, para Eurico, o prestígio dos velhos senhores das fazendas, fazendo surgir, no seu lugar, um outro agrupamento de plutocratas, geralmente comerciantes puros, ou seja, pessoas que desenvolviam nas atividades comerciais a sua atividade chave, não sendo fazendeiros de origem. ${ }^{10}$

O aumento de valores circulantes não passa despercebido por Eurico. Ao longo da sua obra magna, ele estabelece contrapontos com o que considerava o poder solvente do dinheiro. Defende que as fortunas construídas com a nova moeda silenciavam as verdadeiras riquezas produzidas com a força do trabalho vertical de vaqueiros e fidalgos, introduziam valores estranhos à sociedade pastoril e, em certa medida, destroçavam equilíbrio dos velhos solares rurais. Na procura de uma metáfora para definir a classe 
social que ascende na fartura do papel-moeda, o poeta baiano chega à noção de engordadores de bois, aqueles que ficam de olho apenas nos lucros trazidos pela gordura do gado, no prazo estrito da venda. Esta forma de criatório traria bois sem biografias, vendidos anônimos nas ruas da cidade necessitada de carne, a "industrialização da carne para agüentar a urbanização amanhecente” (BOAVENTURA, 1989, p. 410).

A contraposição entre as duas formas de criar, a antiga que produzia biografias bovinas e a dos engordadores, preocupados apenas com o momento do abate, conduz o leitor de Fidalgos à construção de uma analogia com a superação das manufaturas pela produção industrial. Por definição, a produção em série afasta o produtor do que foi produzido, ele participa de uma etapa do processo, não o controla mais inteiramente. Essa alienação conduz, de maneira inevitável, ao esquecimento dos saberes nascidos da produção artesanal, em geral ensinados nas oficinas, passados pelo costume e pela oralidade. No espaço deste saber consuetudinário, constitui-se outro, afastado do universo da produção.

$\mathrm{Na}$ alegoria desenvolvida por Eurico, na qual a Guerra de Quatorze é a deflagradora da Revolução Industrial, o curral substitui a oficina. Referência mítica na narrativa euriquiana, este espaço transcende a noção de mais um cômodo na estrutura da fazenda, é o marco de fundação da Bahia sertaneja, mecanismo de semeadura de uma civilização mestiça pelo interior brasileiro e da fixação do homem no sertão (BOAVENTURA, 1989, p. 24). Além de servir como ponto de apoio para a penetração do gado, e do homem, até o fundo do sertão, era também o pequeno território no qual se aprendiam as técnicas de curas tradicionais, o manejo com o gado, as formas de amansar os animais. Dentro dos pequenos territórios isolados por cercas de cama, ${ }^{11}$ eram desenvolvidos verdadeiros torneios durante as ferras dos animais, as vacinações e mesmo o processo de amansamento de muares. As pugnas eram ritos de passagem para garotos que iriam ingressar no mundo masculino mediante provas de força, destreza e, principalmente, coragem.

Todas estas tarefas eram feitas, segundo a visão do poeta baiano, sem distinção de classes, com a participação de todos os moradores da fazenda (BOAVENTUTRA, 1989, p. 26), diria até, que, nas trocas simbólicas que configuravam a sociedade sertaneja, era importante aos patrões demonstrarem coragem pessoal, destreza na condução de animais como forma de construir um capital social diante dos empregados e agregados.

O trabalho coletivo, os ritos de passagem, os aprendizados da veterinária rural, faziam dos currais locus de exercício de uma forma de memória que chamarei, seguin- 
do a trilha proposta por Ricouer, de habitual (RICOEUR, 2006, p. 99). Essa memória possui um caráter imediato nos procedimentos de lembrança e funciona como centro de equilíbrio da estrutura social, realizando-se entre o hábito e a coerção ao não habitual, ao inovador. O habitus, como define Elias, é o instrumento de formação da economia psíquica dos indivíduos e, portanto, de organização e reprodução das estruturas sociais (ELIAS, 1994, p. 262). A destruição do curral mítico, percebida por Eurico, na denúncia contra os engordadores, transformava em cinzas o espaço formador de masculinidades, o lugar da formação de homens eretos, verticais ao sol.

Um índice importante da substituição das formas de manejo do gado surgiu em Feira de Santana, mais precisamente na antiga Estrada das Boiadas. O ano era 1942, depois de anos de promessas e reivindicações, era inaugurado o novo Campo do Gado, ou como preferiam escritores e jornalistas, os Currais Modelo (BAHIA, 1986, p. 14). Investimento vultoso da Prefeitura Municipal, cujo gasto na construção foi equivalente a mais da metade do orçamento de um ano (Tomando-se 1940 como referência), o Modelo foi saudado com muito entusiasmo, e a preparação da inauguração foi uma exposição de bovinos, certamente uma boa indicação das preocupações em garantir planteis de qualidade para a engorda (CARVALHO, 1940, p. 8). O mais conhecido jornal da cidade não se conteve diante da novidade e estampou na primeira página: "Inaugurado com solenidade o maior mercado de gado do Brasil, em Feira". Além do ufanismo do autor da manchete, bem em moda em tempos de Segunda Guerra Mundial, um trecho da nota que descreve o formato dos currais permite divisar importantes mudanças na forma de guardar e cuidar do gado:

Os currais, de várias dimensões, mas todos feitos de madeiras duras e fortemente cravejadas, são calçados a pedra britada o que não permitem que venham a se formar lameiros prejudiciais ao próprio gado. São em número de 47 , comportam cinco mil bois e se comunicam por espaçosos corredores com balanças, cuja plataforma resistente e solidamente gradeada é provida de corrediças destinadas à entrada e a saída dos lotes de reses, após a pesagem. ${ }^{12}$

Em oposição aos currais de cerca de cama, a estrutura montada no Modelo caracteriza-se por uma perspectiva industrializante, na qual os corredores permitiam o manejo do gado com poucas pessoas, sem a necessidade da presença de cavalos, laços ou uso de força física. Além disso, o trabalho, nesta forma de curral, era muito mais seguro, inviabilizando espetáculos de afronta à coragem, ou o uso do espaço como uma escola de formação de rapazes valentes. A função de ser modelar logo se efetivou; 
ainda na década de 1940, outros currais semelhantes eram produzidos na zona rural de Feira de Santana, permitindo a socialização das práticas de manejo bovino por outros lugares do município. ${ }^{13}$

A substituição das formas de tratar os animais, a segurança representada pelos Currais e a diminuição do número de homens necessários para o manejo de bovinos podem ter colaborado com a diminuição drástica de uma prática comum: o hábito de alguns vaqueiros fazerem correrias pelas artérias da urbe em busca de reses fugidas do antigo Campo. Este, por ser próximo do centro da cidade, facilitava a vida de cavaleiros que gostavam de se exibir em façanhas de equitaşão, perseguindo bovinos fugidos pelo centro da cidade, fugas, aliás, que eram muito de industria, provocadas, como lembra um dos reclamantes. ${ }^{14}$ Esse comportamento mereceu de simples reclamações, até uma forma de criminalização, com edição de portarias por parte do Delegado regional. ${ }^{15}$

Imaginando a cidade como escrita, na qual "cada novo edifício inscreve-se no espaço urbano como uma narrativa em um meio de intertextualidade" (RICOEUR, 2006, p.159), a substituição do Campo do Gado pelos Currais Modelo aponta na direção da produção de uma urbe que suprimia os traços de ruralidades existentes, substituindo-os por uma organização social que privilegiava a rapidez dos serviços, a segurança, a higiene. Seguindo a trilha proposta por um conhecido sociólogo francês, diria que a obra inaugurada naquele ano de 1942 era uma metáfora concreta de um modelo de urbanização que os empreendedores pretendiam baseado na técnica e na economia de recursos (MONS, s/d, 27). Alguém já disse que ler a cidade é fazer uma leitura da esfera pública (BOLLE, 1994, p. 288). A construção dos Currais Modelo, permite perceber uma intencionalidade por parte do poder público, a construção de uma imagem de Feira como a cidade mais importante do interior do Estado, por um lado, e, por outro, uma urbe que retirasse de cena os rastros do passado pastoril, guardando-os em lugar seguro, preferencialmente longe do centro urbano.

No antigo lugar onde eram comercializados gados, outros estabelecimentos foram construídos, alterando a imagem de cidade com a qual Eurico estava habituado. Exatamente onde ficava o Campo, foi construído, na segunda metade da década de 1940, o Abrigo Nordestino, misto de bar, restaurante, ponto de ônibus e, na maioria dos casos, passagem para casais, mocinhas e pretendentes que faziam o footing pela larga Avenida Senhor do Passos. Ainda na mesma área, os jovens poderiam encetar namoricos e conversas no recém inaugurado Cine-Teatro Íris “... considerado o melhor do estado e dos melhores do Norte do Brasil". ${ }^{16}$ Mas não eram apenas estas as transformações 
ocorridas na cidade. Na carta de Hugo Silva, citada anteriormente, existe referência a uma pequena topografia dos novos centros de sociabilidade, o Tênis Clube ${ }^{17}$, o Cassino Irajaj $^{18}$ e os Dancings Clubs. Para o articulista de esportes da Folha do Norte, eram lugares onde os mocinhos da Feira poderiam se realizar, ensaiando passos de cabaritier. ${ }^{19}$

O clima instalado na cidade era de disputa entre núcleos formadores de sociabilidades. Por um lado, as tradições de um núcleo urbano criado a partir do universo rural e que tinha neste a sua principal atividade econômica. Do outro, uma urbanização crescente que punha em questão as sociabilidades tradicionais, uniformizava a urbe deformando a velha paisagem. $\mathrm{Na}$ interpretação de Eurico, este conflito entre os dançarinos formados nas matinês e os vaqueiros instruídos nos currais tinha ligações com a destruição dos lugares que caracterizam a sociedade pastoril:

Em poucos meses, uma boiada, engordando, traria lucro ao pasto. Outro elemento aliado ao burburinho do urbanismo. Enfraquece a dieta do trabalho rural e antepõe ao brilho social das fazendas a vida encantadoramente feminina das cidades. No Feira Tênis Clube, no Clube de Campo Cajueiro, o luxo dos engordadores de agora, a vida fácil dos seus filhos endinheirados. [Grifos do autor] (BOAVENTURA, 1989, p. 416)

Essas memórias, supostamente nascidas do luxo e da riqueza, são objeto de críticas na escrita de Fidalgos. Eurico procurou demonstrar que as práticas sociais que as criavam, atuavam no sentido de silenciar outras, nascidas das organizações pastoris. $\mathrm{O}$ aparecimento de memórias encobridoras, como lembra Freud, cria áreas de interdições nos procedimentos de lembrança, lançado ao esquecimento o que não deve ser lembrado (FREUD, 2006, p. 43). A escolha do autor para começar a crônica citada na abertura destas anotações, o comerciante que teria enriquecido durante a Primeira Guerra, é um bom índice das posições acerca da substituição de memórias. Seu nome completo era Bráulio Euclides de Miranda. Na lista de pagadores de impostos de 1914, sob a rubrica Industrias e profissões, ele aparece como proprietário da única loja exclusivamente de ferragens da praça. ${ }^{20}$ Nas relações dos Conselheiros Municipais, eleitos das décadas de 1910 e 1920, este comerciante não aparece, dado que pode indicar que o mesmo não angariou muito prestígio na sociedade local. ${ }^{21}$ Por outro lado, o imposto recolhido aos cofres públicos, nos anos subsequentes a 1914, não sofre alterações sensíveis, o que pode demonstrar que, se houve enriquecimento, não o foi de maneira tão ostensiva como pode fazer entender o texto de Eurico. Fica como questão entender a escolha de Miranda para ilustrar o texto. ${ }^{22}$ 
Creio que a explicação pode ser iluminada por Fidalgos e seguir duas pequenas variantes: a primeira, o tipo de mercadoria vendida pelo comerciante e a segunda, o destino das fortunas sem biografias, ou seja, que não eram originárias do que o autor chama de fidalguia pastoril e que compunham uma casta de plutocratas cujas famílias estavam diretamente vinculados à fundação de Feira de Santana.

As ferragens são ilustrações da sociedade industrializada. No mundo fechado da fazenda euriquiana eram um dos poucos artigos oriundos da cidade fiscalista que penetravam pelas malhadas, levando para dentro dos solares as suas condições de produção, tomando o lugar de outros, geralmente de madeira, produzidos no âmbito da zona rural. Também nestas lojas eram vendidos artigos que traziam novidades do viver urbano, sobretudo dos grandes centros, bicicletas, carros de mão de ferro, o carrinho para crianças, entre outros. Os empreendimentos comerciais deste tipo foram portas de contato mais visíveis com modelos de urbanidade de outros centros. Através dos seus reclames, a organização espacial das cidades penetrava nos lugares mais distantes.

À edificação do prédio, símbolo de um novo modelo de construção no centro da cidade, soma-se a escolha do tipo de empreendimento, forma de uma prática de urbanização que ocupa progressivamente a vida auto-suficiente das casas-de-fazenda e os reflexos desta em Feira de Santana. As ferragens vendidas são mecanismos de substituição de práticas de construção, de organização de trabalho, de brincadeiras, em suma, das formas de fazer-se sertanejo. A opção por um comerciante de ferragens, único do tipo durante a primeira infância de Eurico, não é, portanto, uma simples coincidência, reflete o objetivo do autor de dialogar com uma forma de fazer o urbano que apagava as formas de lembrar de uma cidade ruralizada.

Raciocínio semelhante pode ter sido desenvolvido na opção pelo nome de Bráulio Miranda. Como disse anteriormente, o comerciante citado por Eurico não galgou nenhum dos degraus que o autor considerava importantes para assumir uma posição de prestígio. Não pertencia a nenhuma das famílias de pastores que organizaram o espaço feirense, não foi Conselheiro Municipal, fazendeiro ou mesmo vaqueiro de fama. Ele só enriqueceu na Guerra de Quatorze, apenas. E assim como ficou rico, pelo que nos fala o poeta, desapareceu na agitada forma de escrever a história da cidade. Foi soterrado por um prédio de três andares que, como um palimpsesto, escreveu sobre a escrita da vida de Miranda uma outra narrativa.

A escolha e as consequentes ilações são reveladoras de uma das mais fortes tensões em Fidalgos; entre a fidalguia conquistada com o trabalho duro, com a cora- 
gem de quem teria desbravado o sertão e a vitória do dinheiro. Sobre o primeiro aspecto da dicotomia, Eurico fala da elaboração de uma cultura imaterial, cujos principais pilares são a honra, a valentia e a valoração do trabalho coletivo. Transmitidos pela oralidade e pelas práticas laborativas, estas noções seriam fundamentais para a estruturação da sociedade sertaneja e constituíam o principal referencial para a articulação das memórias de fundação da região de Feira de Santana. É possível falar de uma economia moral do trabalho sertanejo na obra maior do escritor feirense, trabalho movimentado pelas trocas imateriais do viver coletivamente, pelo fideicomisso entre fazendeiros e vaqueiros e, principalmente, pelo sentimento de que é honroso o suor oriundo das lides do campo.

Por outro lado, na leitura de Eurico, o dinheiro fácil, desvalorizado pela Guerra e pelo Movimento de Trinta, criou uma circulação de valores materiais que funcionou como solvente das relações baseadas na palavra ou na tradição. $O$ trabalho coletivo foi substituído pelo individual, remunerado em moedas. O tempo da tarefa não mais era norteado pelo sol e sim pelas horas de trabalho, pelos programas de rádio ou pelo relógio do patrão. A relação, soldada pela tradição, seria substituída por um contrato de trabalho com partes individuadas e de interesses conflitantes. Operários que nunca ouviram falar em Marx (BOAVENTURA, 2006, p. 33), logo passariam a organizar sindicatos, lutas e greves, coisas que tornavam estranha a cidade que um dia fora do silêncio e da melancolia. Relações impessoais substituíam as de amizades, estruturas feitas para a realização de comércio apareciam no lugar das casas comerciais que eram extensões da casas de famílias (BOAVENTURA, 2006, p. 32).

Hoje a vida é uma descarga de eletricidade. Nem há mais sempre um fardo, um caixote, à guisa de escabelos, para a prosa da tarde. Há cafés. Paga-se antes de tomar-se o café. E café em pó, apressado. Paga-se com uma ficha antes de receber-se a xícara. Conversa-se nas portas dos cafés de todo mundo. Entabulam-se negócios, firma-se até promissórias bem gordas, ao tempo em que o café vai servido. (...) Fala-se muito. Só não se criam aquelas velhas amizades que as antigas palestras alimentavam. Fazem-se conhecimentos, mas que um aval qualquer desfaz. (BOAVENTURA, 2006, p. 95)

Falando sobre a invenção do fósforo, Benjamin destacou o papel de inovações que podem com um simples gesto disparar processos complexos (BENJAMIN, 1989, p. 125). A presença das fichas no comércio impunha modificações nos comportamentos públicos, como o anonimato dos fregueses, necessidade de rapidez no atendimento e filas para comprá-las. Por sua vez, estas mudanças disparavam contra outras 
maneiras de organização das sociabilidades, conspiravam contra velhas hierarquias, ao tempo em que homogeneizavam os compradores, distanciavam amigos com a agilidade dos negócios e punha em questão a noção de temporalidade que permitia aos clientes descansarem calmamente enquanto praticavam a Palestra. Usada com o sentido arcaico de conversa e certamente remetendo à idéia original de encontro para convescotes e socializações, essa prática estava ameaçada por um tempo nervoso, sequioso de agilidades. Um pequeno comentário jornalístico permite a observação de como eram visualizadas estas formas de contato por setores da imprensa feirense. Com o pretexto de comentar uma codificação para pedestres feita pelas autoridades de Buenos Aires, um jornalista local produziu algumas ilações sobre o uso do espaço público para encontros, com o título de Regulando o trânsito do pedestre escreveu:

A essas regras bem poderiam ser aduzidas as seguintes:

Proibição de cordões familiares pelas calçadas.

As palestras e as conferências no meio do passeio.

O estacionamento demorado nos lugares por onde se estabelece o tráfego. ${ }^{23}$

As confraternizações diárias, que funcionavam como elemento socializador, lugar de produção de memórias e de introdução das crianças no universo dos adultos (BOAVENTURA, 2006, p. 92), eram transformadas em estorvo aos caminhantes, deveriam ceder lugar à necessidade de passagem, à agilidade das compras, ao compasso nervoso dos relógios. Esse processo de desaparição ante a urbanização, funcionava como uma condenação das formas de memorar baseadas na oralidade. No lugar das falas impunha-se marcas de lembrança não orais.

$\mathrm{Na}$ contramão dessa forma de fazer a cidade, Eurico propõe, em Fidalgos, uma visão oralizada da história de Feira de Santana. No processo de reconstrução, o autor escreve-a a contrapelo dos sentidos estabelecidos no centro urbano. O ponto de partida foi a valorização do testemunho pessoal como fonte de elaboração do discurso historiador, é a fala da autoridade consagrada pelas palestras, pela escuta atenta de narrativas nas varandas das casas-de-fazenda e não pela formação em alguma academia. (BOAVENTURA, 1989, p.11) À escolha do testemunho, acrescenta-se a primazia do oral como documento, mesmo quando contraposto ao escrito, é a tradição oracular da cidade que socorre Eurico na construção do seu texto. (BOAVENTURA, 1989, p. 405) Como resultado das escolhas pela oralização da narrativa escrita, o autor propõe também, na bela alusão à casa da família, a reconstrução de rituais narrativos 
como forma de comunicação da experiência, de construção de memórias para sobreviver ao silenciamento da urbanização (BOAVENTURA, 1989, p. 11).

\section{$\operatorname{son}$}

\section{NOTAS}

1 Como não me dedicarei à fase de encantamento neste texto sugiro a leitura do poema "Canção da cidade amanhecente”. Cf. BOAVENTURA, Maria Eugenia (Org.). Poesia. Salvador: EGBA, 1990, P.47.

2 A título de exemplo: na sessão do dia $1^{\circ}$ de fevereiro de 1952 foi aprovado um requerimento do vereador Francisco Pinto para denominar Simões Filho uma das ruas do Bairro Ponto Central. Para justificar o autor falou dos relevantes serviços prestados à cidade pelo então Deputado para a chegada da água encanada. Livro de Atas da Câmara Municipal de Feira de Santana, vol. 1, p. 91.

3 Maço de Pareceres do Conselho, Arquivo Público Municipal de Feira de Santana (APMFSA). O parecer é datado de 28/08/1926.

4 Sobre a Rio-Bahia, Cf: jornal Folha do Norte de 09/04/1949, p.1. Arquivo do Museu Casa do Sertão/Centro de Estudos Feirenses (MCS/CENEF).

5 Os dados do Censo do IBGE para a população urbana são: 19.660 em 1940; 34.277 em 1950 e 69.884 em 1960. Cf. SOUZA, Eronize. Prosas de valentia: violência e modernidade (1930-1950). UFBA, 2008, p. 28.

6 SILVA, Hugo Navarro. Meu caro Aloísio. In: jornal Folha do Norte de 13 de janeiro de 1951, p. 1, número 2166. Arquivo do MCS/CENEF.

7 Livro de Plantas da Prefeitura Municipal, 1949-1953. Sala dos Livros, número 137. APMFS.

8 Livros de cobrança da Décima Urbana, 1952. Sala dos Livros, número 90-1, APMFS.

9 Anúncio publicado no jornal Folha do Norte de 07/04/1951, p. 2, número 2178. Arquivo MCS/CENEF.

10 A compra de uma fazenda para veraneio é um traço marcante na trajetória de um comerciante feirense, dos mais influentes na cidade ao longo do séc. XX. Cf: FALCÃO, João. A vida de João Marinho Falcão: a vitória do trabalho e da honra. Brasília: PAX Editora, 1993, p. 67.

11 As cercas de cama eram construídas com uma série de estacas dispostas em pares. Para fazer a vedação eram colocadas toras de madeira deitadas entre as estacas e apoiadas sobre pedras, por isso o nome. Todo trabalho era feito de maneira artesanal, inclusive a amarração das estacas.

12 Folha do Norte de 28/02/1942, p. 1, 1703. Arquivo MCS/CENEF.

13 Entrevista com ASO. Um dos currais indicados era o da Fazenda Olinda, pertencente a um dos irmãos do então Prefeito Heráclito Dias de Carvalho, Pedro Dias de Carvalho.

14 Folha do Norte de 23/04/1932, p.1. Arquivo MCS/CENEF.

15 Folha do Norte de 21/09/1932, p. 1. Arquivo MCS/CENEF.

16 Folha do Norte de 20 de julho de 1946, p.3, número 1931. Arquivo MCS/CENEF.

17 O Feira Tênis Clube foi fundado em 08/12/1944 segundo os estatutos do clube. Cf: Arquivo do Feira Tênis Clube.

18 Aberto em 23 de fevereiro de 1946, segundo convite publicado na p. 3 da edição da Folha do Norte do mesmo dia, que circulou com o número 1911. Arquivo MCS/CENEF. 
19 SILVA, Hugo Navarro. Meu caro Aloísio. In: jornal Folha do Norte de 13 de janeiro de 1951, p. 1, número 2166. Arquivo do MCS/CENEF.

20 Cobrança do Giro do Imposto de Industrias e Profissões, In: Folha do Norte de 25/04/1914, p. 3, número 218. Arquivo MCS/CENEF.

21 Livros do Conselho 1916-1930, APMFS.

22 Livro de Indústrias e Profissões. APMFS.

23 Folha do Norte de 15/02/1941, p. 3 número 1649. Arquivo MCS/CENEF.

\section{REFERÊNCIAS}

BAHIA, Juarez. Setembro na Feira. Rio de Janeiro: Nova Fronteira, 1986.

BENJAMIN, Walter. Charles Baudelaire um lírico no auge do capitalismo. Tradução de José Carlos Martins e Hemerson Alves Baptista. São Paulo: Brasiliense, 1989. Obras escolhidas, vol. III.

BENJAMIN, Walter. Magia e técnica, arte e política. Tradução de Sérgio Paulo Rouanet. $6^{a}$ edição. São Paulo: Brasiliense, 1993. Obras escolhidas, vol. I.

BOAVENTURA, Eurico. Fidalgos e vaqueiros. Salvador: EDUFBA, 1989.

BOAVENTURA, Maria Eugênia (org.). A paisagem urbana e o homem: memórias de Feira de Santana. Feira de Santana: UEFS, 2006.

BOAVENTURA, Maria Eugenia (Org.). Poesia. Salvador: EGBA, 1990.

BOLLE, Willi. Fisiognomia da metrópole moderna: representações da história em Walter Benjamin. São Paulo: Edusp, 1994.

CARVALHO, Heráclito Dias de. Relatório da Prefeitura Municipal de Feira de Santana. Feira de Santana: Silva e irmãos, 1940.

CERTEAU, Michel de. A invenção do cotidiano: artes do fazer. 9 $^{a}$.edição. Tradução de Ephraim Ferreira Alves. Petrópolis: Vozes, 2003.

ELIAS, Norbert. O processo civilizador. Tradução de Ruy Jungmann. Rio de Janeiro: Jorge Zahar, 1993. Vol. I.

FALCÃO, João Marinho. A vida de João Marinho Falcão: vitória do trabalho e da honra. Brasília: PAX Editora, 1993.

FREUD, Sigmund. Sobre a psicopatologia patologia da vida cotidiana. Tradução de Vera Ribeiro. Rio de Janeiro: Imago, 2006. Obras psicológicas completas, vol. VI.

GINZBURG, Carlo. Mitos, emblemas, sinais: morfologia e história. Tradução de Federico Carotti. São Paulo: Cia das Letras, 1999.

HALBWACHS, Maurice. A memória social. Tradução de Beatriz Sidou. São Paulo: Centauro, 2006.

LEFEBVRE, Henry. O direito à cidade. Tradução de Rubens Eduardo Frias. São Paulo: Centauro, 2001.

MONS, Alan. A metáfora social: imagem, território, comunicação. Tradução M.F. Sá. Porto: RES, s/d.

NORA, Pierre. Entre a memória e a história: a problemática dos lugares. Projeto História - "Os trabalhos da Memória”. São Paulo, n. 10, 1984, p. 1-27.

PESAVENTO, Sandra Jathay. Muito além do espaço: por uma história cultural

do urbano. Estudos históricos, Rio de Janeiro, n. 16 julho-dezembro 1995, p.279-290.

RICOEUR, Paul. A memória, a história, o esquecimento. Tradução de Alan

François. Campinas: EDUNICAMP, 2007.

SOUZA, Eronize. Prosas de valentia: violência e modernidade (1930-1950). Salvador: UFBA, 2008 (Dissertação de Mestrado). 
Entre currais e modelos: Eurico Alves leitor de Feira de Santana, 1940-1960

Between corrals and models: Eurico Alves as a reader of Feira de Santana city, 1940-1960

\section{RESUMO}

Neste texto analiso as recepções do processo de urbanização de Feira de Santana na obra de Eurico Alves, entre os anos de 1940 e 1960. Exploro, em especial, os conflitos construídos pelo autor entre a desruralização das sociabilidades e o avanço de práticas citadinas, estas imaginadas como mecanismos de apagamento das memórias oriundas do passado pastoril da cidade.

Palavras-chave: urbanização, sociabilidades rurais, memória, esquecimento, oralidade, silenciamento

\section{ABSTRACT}

In this text I analyze the receptions of the urbanization process in Feira de Santana in Eurico Alves's work between the 1940's and 1960's. I explore specially the conflicts constructed by the author between the loss of rural characters of sociability and the advance of urban practices. Those practices are then imagined as mechanisms to erase memories of the local's pastoral past.

Keywords: urbanization, rural sociability, memory, forgetting, orality, silencing

Recebido em 14/06/2009

Aprovado em 20/06/2009

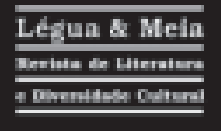

OLIVEIRA, Clóvis Frederico Ramaiana Moraes. Entre currais e modelos: Eurico Alves leitor de Feira de Santana, 1940-1960. Légua \& meia: Revista de literatura e diversidade cultural. Feira de Santana, UEFS, n 5, 2009, p. 20-37.

Clóvis Frederico Ramaiana Moraes Oliveira é Professor Assistente da Universidade do Estado da Bahia (UNEB-Campus de Alagoinhas), Mestre em História Social pela UFBA e aluno do Programa de Pós-Graduação em História da UnB. 